\title{
Paz, Justicia y POSCONFlicto: UNA APROXIMACIÓN DESDE LOS DISCURSOS DE FAMILIAS VÍCTIMAS DEL DESPLAZAMIENTO FORZADO ASENTADAS en Soacha, Cundinamarca
}

\author{
PEACE, JUSTICE AND POST-CONFLICT: AN APPROACH FROM THE \\ SPEECHES OF FAMILIES VICTIMS OF FORCED DISPLACEMENT \\ SETTLED IN SOACHA CUNDINAMARCA
}

\author{
Por: Yuri Alicia Chávez Plazas* \\ José Luis Hernández Hernández** \\ Mario Alberto Rangel ${ }^{* * *}$
}

Recibido: 1 de marzo de 2015 - Aprobado: 9 de julio 2015

\begin{abstract}
RESUMEN
La paz y la justicia en un posible escenario de posconflicto en el país, ha sido un tema ampliamente debatido por académicos y politólogos, sin embargo es necesario aproximarse a los discursos que las víctimas del conflicto armado construyen desde sus daños y esperanzas. El artículo reflexiona en torno a las expresiones que diez familias víctimas del desplazamiento forzado asentadas en Soacha ${ }^{1}$, construyen desde su dramática experiencia en la guerra y sus precariedades socioeconómicas en el municipio. Sin duda todos anhelan la paz, pero con justicia reparativa. La reflexión es el resultado de la investigación realizada por la Universidad Colegio Mayor de Cundinamarca², programa de Trabajo Social ${ }^{3}$, en 2014, que indagó las representaciones sociales que de su condición de víctimas estas familias construyen en el marco de la Ley 1448. Aquí la justicia y la paz, surgieron como categorías emergentes, el diseño fue de corte cualitativo.
\end{abstract}

Palabras claves: Posconflicto, paz, justicia, víctimas, Soacha.

\begin{abstract}
Peace and justice in a post-conflict scenario in the country, has been a topic widely debated by academics and political scientists, however you need to approach the speeches that victims of armed conflict built from his injury and hopes. The article focus on the expressions than 10 victims families forced displacement settled in Soacha, built from his dramatic experience of war and its socioeconomic precariousness in the municipality. Certainly all want peace, but with reparative justice. Reflection is the result of research conducted by the Universidad Mayor de Cundinamarca School, Social Work program in 2014, which investigated the social representations of their status as victims of these families build on the framework of Law 1448. Here justice and peace, emerged as emerging categories, the design was qualitative.
\end{abstract}

Keywords: Post-conflict, peace, justice victims, Soacha. 


\section{Introducción}

l artículo se inscribe en el conjunto de estudios sobre reparación integral

y construcción de paz que se realizan en el país, presenta una mirada a

la Ley de Víctimas y Restitución de Tierras que si bien es cierto, existen amplios estudios, (Bautista Revelo, 2012); (Cortés, 2013), (Luna Jaramillo, 2014), es necesario también, aproximarse a las construcciones sociales que realizan los diferentes actores sociales, en este caso familias víctimas en el conflicto armado.

Empecemos diciendo que la reparación integral corresponde al Estado y su acción debe ser acorde a la naturaleza y magnitud del daño causado, este derecho tendrá aplicación al momento de una violación a los Derechos Humanos o al Derecho Internacional Humanitario, la víctima podrá acceder a medidas de restitución, indemnización y rehabilitación. Cabe advertir que el derecho a la reparación "deberá abarcar todos los daños y perjuicios sufridos por la víctima". (Arce Ortiz \& Moreno Salazar, 2014). En Colombia el esfuerzo más reciente por visibilizar a las víctimas del conflicto armado se encuentra en la Ley 975 de 2005, denominada de Justicia y Paz, la cual terminó beneficiando más a los victimarios que a las propias víctimas, (Duque Muñoz \& Guevara Alzate, 2014); es de recordar las fuertes críticas que recibió de amplios sectores de defensores de derechos humanos, sobre todo en lo relativo a la asistencia, posteriormente vendrían decretos que buscaban subsanar esta deficiencia, (Uprimny, 2006). Sin embargo es con la Ley 1448 de 2011, denominada Ley de Víctimas y Restitución de Tierras que empezó a ser adoptada por las autoridades locales el 1 de enero de 2012, donde se busca dignificarlas mediante la realización de sus derechos constitucionales. Se entienden como víctimas "aquellas personas que individual o colectivamente hayan sufrido un daño por hechos ocurridos a partir de 1 de enero de 1985, como consecuencia de infracciones al Derecho Internacional Humanitario o de violaciones graves y manifiestas a las normas internacionales de Derechos Humanos, ocurridas con ocasión del conflicto armado", (Ley 1448 de 2011), en el marco de esta ley el desplazamiento forzado es considerado un hecho victimizante y es el que mayor número de personas registra en el territorio nacional.

Así mismo, con esta Ley, el Estado adelanta acciones de atención, asistencia y reparación orientadas a que las victimas puedan ejercer con plena garantía su ciudadanía, a 2014 "la entidad ha atendido más de 2 millones 400 mil solicitudes en 85 puntos de atención, se ha reconocido la condición de victimas a un total de 394.521 personas y se han indemnizado administrativamente a 130.761." (Unidad de Víctimas, 2014), sin embargo desde el informe de Seguimiento y Monitoría realizado por la Contraloría, Procuraduría y Defensoría del 
Pueblo, (De la Nación, 2013), estos resultados son pobres, considerando el número de víctimas y la crisis humanitaria en que viven. Entre las principales dificultades para su implementación e identificadas por los órganos de control se encuentran: el carácter fundamentalmente asistencial y muy distante de una verdadera reparación integral y de su concepción progresista, la escasa participación de las víctimas, el incumplimiento en los compromisos presupuestales, entre otros. En el informe, también se observa lentitud en la conformación del registro único de víctimas, debido a demoras en el proceso de toma de la declaración, valoración, inscripción y notificación acerca de su inclusión en el sistema.

La paz por su parte, adquiere importancia en al concierto internacional después de la Segunda Guerra Mundial, convirtiéndose en tema en diferentes escenarios políticos y académicos. En Colombia es desde la década de los 80, cuando la terminación de un largo y cruel conflicto armado empieza a ser la esperanza tanto de políticos, académicos y de la sociedad en general, varios estudios dan cuenta de ello. De acuerdo a Nasi, (2005), es posible identificar en América Latina acerca de análisis de procesos de paz concretos, por ejemplo los trabajos desarrollados por Bejarano, 1999, Medina y Sánchez, 2003, Valencia 2002 y Loaiza, 2012, entre otros.

Sin embargo, al hablar de construcción de paz se plantean varios dilemas, para Rettbergg (2003), esta se encuentra estrechamente relacionada con la posibilidad de superar las secuelas específicas del conflicto, la necesidad de parar la guerra y generar las condiciones para el desarrollo económico y la inclusión social, por su parte Archila (2001), la vincula a iniciativas de movimientos sociales o de acción y en mucho casos con carácter reivindicativos. Por otro lado Sacipa, (2005), aproximándose al significado que ciudadanas y ciudadanos en Bogotá le otorgan a la paz, concluye que para los encuestados no hay en el país líderes políticos que abanderen estos procesos y que es necesario desarrollar procesos sociales, políticos, culturales y psicosociales para construirla. En este sentido, no se desconoce que en Colombia se han presentado diversos escenarios de construcción de paz desde la sociedad civil, expresados en múltiples iniciativas debido al impacto de la violencia generada por actores armados o momentos de militarización; por su parte Delgado, (2009), en su libro Resistencias para la paz en Colombia, identifica en las experiencias de resistencia civil dos elementos, la búsqueda de una paz integral y perfectible, integral porque incluye diversas dimensiones de los seres humanos y colectivos y plantea la necesidad de superar la pobreza y la exclusión, así como la creación de escenarios de convivencia pacífica y cultura de paz y perfectible entendida como proceso inacabado soportando 
en el empoderamiento pacifista, la búsqueda de bienestar y prácticas de gestión y resolución pacífica de conflictos. Aunque a nivel general en el país prevalece una concepción de paz como la ausencia de un conflicto armado con las guerrillas. (Castellanos, 2014).

Ahora bien, es importante entender que "para poner fin a un conflicto armado interno, el objetivo de la reconciliación nacional plantea la necesidad de encontrarle salidas a los reclamos de verdad y de justicia que incluyen exigencias de reparación a las víctimas", pero también, de acuerdo al Ministerio del Interior, "la aplicación de un modelo de justicia transicional implica una transformación social, porque si este se basa en una brecha de desigualdad social, puede en cualquier momento estallar en el resurgimiento del conflicto". (Ministerio de Interior, 2011, pág. 8). En este sentido, la justicia transicional no solo debe evitar la violación a los derechos humanos, sino asegurar a las víctimas el derecho a ser reconocidas, reparadas, a conocer la verdad y garantizar la no repetición, en este sentido se comprende que la "lucha por el derecho, por un derecho que aspire a la justicia constituye hoy día una importante forma de pacifismo activo". (García Inda, 2011, p.73).

Sin duda, la construcción de una paz duradera en Colombia va más allá de las negociaciones de La Habana y futuros diálogos con los demás actores armados, es necesaria una política de estado y su articulación con la sociedad civil para garantizarlo, profundos cambios sociales, económicos y de política social, son fundamentales a fin de superar las desigualdades resultados de un modelo socioeconómico que ahonda la inequidad.

\section{La paz: frente a la posibilidad de perdón}

"Lo que nosotros queremos es que sea real la constitución, que sean reales nuestros derechos, que sean reales libertades para que vivamos en un país en paz." (Testimonio).

Pero también, la paz requiere de legitimidad social y política, pues para las familias víctimas del conflicto armado, su posibilidad de generar ambiente de convivencia en paz ha de estar ligada a objetivos de reparación integral, el derecho a la verdad, justicia, y garantía de no repetición.

En relación con la garantía de no repetición, el testimonio de las víctimas señalan "...no pueden garantizar la no repetición de los hechos porque seguimos en la repetición de los hechos y es lo que dice la ley 1448 que no van a volver a 
repetirse hechos y acciones y vea que se ha hecho repetitivo en cuanto a la historia, las causas y por ende todas las consecuencias de las causas que se dan, ies que no cambia!". (Testimonio). Para la mayor parte de las familias entrevistadas vislumbrar escenarios de paz es una realidad lejana debido a las condiciones de inseguridad en los sitios de salida, que no han cambiado pues tienen conocimiento de nuevas víctimas, además de las dificultades en los sitios de asentamiento debido al carácter asistencial de una política que los convierte casi en mendigos de la ayuda estatal, que tiene dificultad en reconocer las particulares de los desplazados, los llena de temor y les impide la formulación de un nuevo proyecto de vida lo cual a su vez los aleja de objetivos de paz (Vargas, 2011), lo anterior es corroborado en el siguiente testimonio, "mi hija ya se fue, y le tocó devolverse porque no se pudo estar allí, la verdad como le digo la situación aquí es dura y ellos tiene tres niños y a pesar de que ellos están jóvenes, pero era dura y entonces que les toco antier llegar otra vez, volver nuevamente acá porque no pudieron hacer nada, porque como me dice ella, no mamá eso allá está feo, es una mentira que esa gente está quieta, que hay paz, la paz la están haciendo ellos allá, pero en el campo está igual la situación, allá no está ahí sí como el cuento, eso es lo que uno no cree". (Testimonio). Como plantea Rettbergg, la paz para las familias se relaciona con la necesidad de parar la guerra y generar las condiciones para el desarrollo económico y la inclusión social.

La construcción de escenarios de paz en el país exige escuchar a las víctimas, acudir a sus relatos y memorias, comprenderlas como sujetos en permanente construcción, capaces de incidir significativamente en su futuro, puesto que imponer una idea de paz que no corresponde a su realidad, no es lo más acertado, ya que son ellos quienes son los más comprometidos en alcanzarla. La realidad que viven estas familias víctimas de desplazamiento forzado, exige el respeto a su dolor y el clamor para que los responsables digan la verdad y se comprometan a no repetir los hechos victimizantes: "Deberían estar de la mano, la paz y la justicia porque si hay una investigación clara y efectiva pues entonces va a ser más fácil, entonces debería haber un equilibrio entre la consecución de la paz y la justicia". (Testimonio). Desde los discursos de las familias, sin duda como plantea García, (2011), la justicia es la mejor forma de pacifismo, entonces será necesario agilizar las investigaciones y facilitar el acceso de las víctimas a los sistemas judiciales, pero también fortalecer las medidas de reparación simbólica.

En relación con la reparación integral los testimonios señalan que además de la ausencia del conflicto armado la paz debe generarse en condiciones de equidad social, "No, yo creo que es más importante para nosotros conseguir la paz pero una paz verdadera y que garantice los derechos fundamentales de las personas, 
porque he ahí el caldo de cultivo para la guerra, de que no se han garantizado los derechos, la vivienda, salud, educación de calidad, proyectos de desarrollo para todos. Porque la realidad es que el campesino tampoco tiene subsidio de ningún tipo". (Testimonio). Generar la inclusión social y lograr la reparación integral corresponde al Estado y debe ser acorde no solo a la naturaleza y magnitud del daño causado, sino a un modelo de desarrollo que garantice un bienestar para todos.

Es claro que desde el discurso de las familias víctimas el perdón se encuentra ligado a la paz, sin embargo como lo menciona Uprimny (2006), no como perdones amnésicos, inaceptados en los tratados internacionales sobre derechos humanos, más como un perdón compensador, que pretende encontrar un equilibrio entre las exigencias del castigo a los victimarios y los derechos de las víctimas, pero sobre todo se acerca a un perdón responsabilizante, basados en la forma de negociación de paz que toman seriamente en consideración los derechos de las víctimas a la verdad, la justicia y la reparación y los deberes del Estado para garantizarla. Recordemos que los diálogos de La Habana en el quinto punto se refiere a la necesidad de resarcir a las víctimas, lo cual empieza por reconocerlas, sin embargo las FARC han negado su culpabilidad en los diferentes hechos victimizantes y la exigencia de la sociedad civil de pedir perdón por la violación de los derechos humanos, lo que ha generado es que este aspecto en la agenda sea de los más controvertidos. En un proceso de paz en el que se muestra a las víctimas como un aspecto fundamental, son pocos los avances hasta ahora.

La construcción de un perdón responsabilizante requeriría, también, de un proceso psicosocial con las víctimas dadas las percepciones que se tienen frente al perdón y a los profundos daños generados en la guerra. "Sí, el perdón es personal, cada quien trabaja su caso, por ejemplo yo no podía entrar a una funeraria mire yo temblaba, por lo menos estuve en tratamiento psicológico y ya pude ir a dos funerarias. Entonces yo creo que todo es personal y de acuerdo a la cultura". (Testimonio), Quizás como plantea Sacipa, (2005), no se identifican líderes políticos frente a los procesos de paz, pero desde las víctimas es posible desarrollarlos, tal y como ocurrió en Argentina en donde el movimiento de víctimas logró visibilizarlas, dignificarlas y exigir justicia. (Giraldo 2004).

Si bien es cierto la intención del actual gobierno de lograr la finalización del conflicto a través de los diálogos con la FARC es deseable, alcanzar la paz y el perdón como elementos fundamentales de la reconciliación nacional, lo cual exige escuchar los reclamos de la población civil, tan solo así se tendrá una paz justa y duradera y en esto desde el discurso de las familias el Estado tiene una 
gran responsabilidad, "porque hay personas que no perdonan por que vieron matar a su familia, pero hay muchas que sí perdonan, eso es más que todo en el tratamiento de las personas por parte del Estado". (Testimonio), queda entonces como reto superar las fallas estructurales en la aplicación de la Ley 1448 de 2011, tal como lo señalan los órganos de control en el país. (De la Nación, 2013).

Prevalece también en los testimonios un significado de la paz como el fin del conflicto con las guerrillas, "Tenemos que perdonar, la sociedad civil tiene que perdonar esa clase de crímenes que ellos cometieron para que haya paz, porque o si no cuando la vamos a tener, porque si seguimos vengándonos, seguimos en una guerra que no va a tener fin". (Testimonio). Lo que demuestra, sin duda, el imperativo de acabar el conflicto armado, pero también de desarrollar estrategias de construcción de paz que permitan superar otras violencias, tales como la urbana, intrafamiliar, para generar realmente ambientes de convivencia social.

\section{Discursos frente a la justicia}

"Entonces nosotros lo que queremos es una paz con justicia social, una reparación con una verdadera justicia." (Testimonio)

Pero si hablar de paz es complicado con las familias en situación de desplazamiento, reflexionar frente a la justicia lo es más, debido al temor que experimentan de que los delitos de los cuales fueron objeto queden en la impunidad. Quizás la presión ejercida por los medios de comunicación frente al perdón como elemento fundamental de la reconciliación, busque obligarlos a olvidar su dolor, pero desde las víctimas se exige justicia reparativa, tal como lo señala el siguiente testimonio "pero que si se haga una verdadera justicia y esto tiene que ver con la verdad, que se esclarezca eso, a través de la justicia, así de pronto se podría presentar una verdadera armonía tanto con las víctimas y la justicia en un posconflicto". (Testimonio). Es claro entonces, que las familias reconocen que las medidas de justicia transicional deben asegurarles el derecho a ser reconocidas, reparadas, a conocer la verdad y garantizar la no repetición. "Tenemos que tener en cuenta que para una paz tenemos que tener justicia". (Testimonio). "La justicia es muy importante para eso, que investigue toda la verdad que necesitamos". (Testimonio), frente a la verdad, llama la atención los reclamos realizados por las familias por la ineficiencia del sistema judicial en el país, sienten que impera la impunidad y la falta de atención estatal frente a la mayoría de los casos. Se sienten desprotegidos por el Estado frente a los victimarios. 
En un posible escenario de posconflicto, los discursos están vinculados con la justicia, las familias entrevistadas no están dispuestos a olvidar, "Yo creo que después de que se dé el proceso de paz si es que se da en el país, la justicia debe fortalecerse". (Testimonio). Lo anterior exigiría la creación de mecanismos y comisiones desde la institucionalidad, pero también la movilización de las víctimas para lograr este objetivo, "pues creo que una de las propuestas está relacionada con las propuestas que hemos hecho porque la justicia en Colombia, es deficiente y se queda impune la gran mayoría de actos de violencia que se deben repudiar, y la justicia es demorada y en casos es imposible acceder a ella, porque los mismos jueces están bajo los ideales políticos del sistema y al sistema no le conviene que se sepa la verdad porque son muchísimas las víctimas que hay que reparar y por eso hacemos la propuesta de una reforma profunda a la justicia para que verdaderamente sea eficiente y más rápida, porque es lenta y termina revictimizando a las víctimas". (Testimonio). Solo así el derecho se entenderá como una forma de pacifismo activo.

De otro lado, los discursos de las víctimas frente a la justicia, van más allá del castigo a los victimarios, lo relacionan con la reparación, lo que se evidencia en el siguiente testimonio, "A mí eso se me asimila porque la justicia entra a hacer parte de una verdadera reparación en nuestro país lo que podría traer un poco de paz". (Testimonio), frente a esto, el informe realizado por la Procuraduría, Contraloría y Defensoría del Pueblo acerca de los avance en la aplicación de la Ley 1448 de 2011, señala que el estado ha sido lento para la atención a los 286.409 predios despojados y las 43,509 solicitudes. (De la Nación, 2013). En relación con la atención a población en situación de desplazamiento son pocos los resultados que permitirían superar el "Estado de cosas inconstitucional" decretado por la Corte Constitucional en la sentencia T-025. (Aguilar, 2014) a eso se le agrega el escaso conocimiento e interés de las familias víctimas frente a esta Ley. "De la restitución de tierras sé, que es cuando de pronto le devuelven a uno las tierras de donde fue despojado, pero hasta el momento yo no he podido hacer nada, porque nosotros solamente tenemos una carta promesa de venta, y hasta que no haiga una escritura no se puede hacer nada sobre eso, nosotros ahí estamos en la perdida porque totalmente lo que se le entrego al señor, o sea lo que se le pago al señor, porque la finca no puede ser devuelta". (Testimonio). "De ley de víctimas pues no conozco nada, pero de donde yo vengo por la vaina de que me sacaron, sí me sacaron por eso estoy por acá y me toco dejar todo por allá botado, claro que yo siempre voy, pero siempre uno la teme, sí uno la teme, siempre uno va como el cuento a las espaldas". (Testimonio). Recordemos que las víctimas solo pueden acceder a las medidas de Ley, si están inscritas en el registro único, razón por la cual es necesario fortalecer los mecanismos de divulgación y acceso a los beneficios de Ley. 
Pero la idea de justicia también va ligada a la responsabilidad que tiene los actores armados y el Estado frente a los delitos cometidos. "Para mí todos los crímenes así sea de una persona es atroz entonces yo considero que no, que deben considerarse todos los crímenes atroces, todas las víctimas, para mí la justicia debe operar igual en todos los casos, debe cobrarse todo". (Testimonio), razón por la cual frente a los diálogos de La Habana se debe escuchar los reclamos de justicia de la población civil, en todos los casos, por cuanto las familias sienten que tan solo se reconocen los llamados casos y víctimas emblemáticas, para ellos todos sus muertos cuentan. "Nosotros siempre hemos dicho que no estamos de acuerdo con una impunidad, ni de los unos ni de los otros, claro hay mecanismos para que seguramente no lleguen a pagar todo lo que es pero si debe haber algo de condena y justicia, porque una cosa son los crímenes que ha cometido el Estado diferente a lo que se haya cometido al otro lado". (Testimonio), estas expresiones son comprensibles en la medida en que las víctimas fueron objeto de múltiples violaciones a sus derechos humanos ante la más absoluta indefensión e impunidad por parte del Estado.

\section{Escenarios de posconflicto: una mirada desde las víctimas}

"Yo le digo que yo no soy víctima, soy desplazada.

Víctima somos todos, desgraciadamente nos dieron ese título de víctima" (Testimonio)

El conflicto armado en Colombia, que a la fecha deja más de seis millones de víctimas de acuerdo a lo planteado por el Grupo de Memoria Histórica (2013, pág. 68), se caracteriza por su persistencia, crueldad y degradación, por lo cual pensar en un posible escenario de posconflicto resulta complejo en la medida en que, por una parte, no se logre superar las condiciones que lo generaron, como lo es la profunda inequidad social que ocasiona que la mayor parte de la población viva en condiciones de pobreza y por otra, la persistencia de grupos insurgentes, bandas criminales y violencia común, que constituyen un clima de inseguridades frente a los anhelos de paz y reconciliación. (Arce, 2014). Para las víctimas, un futuro escenario de posconflicto debe reconocer y resarcir los profundos daños experimentados no solo en la salida abrupta y violenta sino en las dificultades en los lugares de llegada, pues el accionar de los grupos armados transformó sus vidas, comunidades y proyectos vitales, generaron daños que difícilmente podrán ser cuantificados. Pero sin duda el posconflicto exige una conjunción de voluntades y es que al analizar experiencias internacionales, caso Argentina, se puede comprender que aún falta mucho camino por recorrer

tal y como lo menciona Javier Giraldo en su documento Búsqueda de verdad y justicia, seis experiencia de posconflicto (2004), "en donde por momentos las leyes, 
el Estado, los medios de comunicación se orientan a acallar la verdad y favorecer la impunidad"; en este país el papel del movimiento de víctimas fue fundamental a la hora de lograr la reparación integral.

Podría decirse que en el actual contexto nacional las medidas de justicia transicional deberían estar acompañadas de trascendentales cambios sociales orientadas a brindar oportunidades sociales y económicas a la población víctima del conflicto armado, tradicionalmente excluida, así como garantizar el derecho a la verdad, reparación y garantía de no repetición como bases para la construcción de una paz duradera. Sin embargo desde la experiencia de las familias víctimas del desplazamiento forzado en Soacha "las cosas" no han cambiado, sus vidas transcurren entre la inseguridad y la precariedad socioeconómica. "Hay que seguir con las condiciones adversas, situaciones infrahumanas, de desprecio, de discriminación y estigmatización, seguir para adelante tener personalidad y enfrentarse a todo. Porque muchas víctimas no hacen nada, no debemos esconder la condición eso sería ser hipócrita y falso". (Testimonio).

Otro aspecto no menos importante lo constituye la ambigüedad existente al momento de categorizar a las víctimas en el conflicto armado en Colombia, si bien el debate nacional ubica como víctimas actores armados que en su momento fueron victimarios, lo cierto es que los desplazados forzados se sienten víctimas invisibizadas por la sociedad, olvidados por el Estado y revictimizados por los funcionarios de las instituciones como lo refiere una de las víctima. "Bastante, porque aquí lo miran a uno como si fuera poca cosa, como si uno fuera lo peor porque acá dicen que somos unos invasores, o sea como si fuéramos un bicho raro. Porque aquí si se dan cuenta que uno es desplazado peor, ahhh estos desplazados ya vinieron a invadirnos nuestro terreno, y sí somos negros peor... dicen ahh es que estos negros porque no se quedan dónde estaban que estos negros en todo lado andan de metidos. Porque esas son las primeras frases que uno escucha acá". (Testimonio). Por otro lado, la preocupación por la dignidad de la persona humana es hoy universal, la Declaración de los Derechos Humanos la reconocen, y tratan de protegerla y exigir su respeto en la mayor parte del mundo. Los errores que pueda haber en la formulación de esos derechos no invalidan la aspiración fundamental que contienen: el reconocimiento de una verdad fundamental, la de que todo ser humano es digno por sí mismo, y debe ser reconocido como tal. El ordenamiento jurídico y la organización económica, política y social deben garantizar y salvaguardar ese principio. Las familias víctimas del desplazamiento forzado asentadas en Soacha sienten vulnerados sus derechos fundamentales, sobre todo aquellos que se refieren a su dignidad como personas. "porque uno viene al médico y si no lo ven con la cabeza colgando o muriéndose no lo atienden, por ejemplo yo cuando tuve el parto de la niña a mí 
me tocó firmar unos papeles para poder salir de ahí e irme a otro médico para que me atendieran, porque la china ya casi naciendo y no me atendían y ese hospital no sirve para nada, no, no le prestan la ayuda que deben de tener. Pues la salud más que todo y lo del colegio y todo eso uno queda pensando". (Testimonio).

Ahora, el municipio de Soacha es reconocido como uno de los que presenta mayor recepción de víctimas del conflicto armado y en particular del desplazamiento forzado. Se encuentra ubicado al sur-oriente de la ciudad de Bogotá y es considerado un municipio dormitorio; se caracteriza por sus altos índices de pobreza, sus escasas oportunidades laborales y educativas y su marcado deterioro ambiental. En las partes altas del municipio las viviendas históricamente han sido ocupadas de manera ilegal: cabe recordar que en los últimos años se han presentado deslizamientos e inundaciones.

La llegada de población en situación de desplazamiento es permanente. Se calculan que llegan a diario entre dos y tres familias, lo que supone una agudización de la crisis social en el municipio. En los últimos años y debido al escalonamiento del conflicto armado en el suroccidente del país es frecuente la llegada de migrantes forzado del norte del Cauca, Valle y zona Pacifica. (Codhes, 2013), (Alcaldía de Soacha, 2012). Estas personas enfrentan dificultades que vulneran sus derechos y que son referidas por las familias entrevistadas de la siguiente manera, "Pero, ¿las personas que están llegando en estos momentos? ¿Qué creen ustedes? Eso es lo que a mí me llena de tristeza que en estos momentos está llegando tanta población y anteriormente había una ayuda humanitaria y ahora no la hay, anteriormente usted llegaba inmediatamente a tal albergue, pero ahora no hay ni albergue, no hay ni cómo ayudarle a las personas y tienen las personas que dormir en la calle, aguantar hambre y eso es lo que yo pido y especialmente sin ofenderlas por mis raza porque yo trabajo por todos especialmente por mi raza. Entonces eso es lo que yo no sé qué se va a hacer o que se puede hacer respecto a todo lo que está pasando". (Testimonio). En este sentido, mientras prevalezca la situación de crisis humanitaria en las víctimas, el posconflicto será para ellos más lejano. Si bien es cierto, la Ley 1448 de 2011, establece en el artículo 13, el derecho a una atención con enfoque diferencial, desde la perspectiva de las víctimas, lo que no se aplica, pues se sienten discriminados y rechazados por su condición de género, generación, etnia y raza.

Para las familias que llegan a Soacha las profundas consecuencias dejadas por la guerra son claras, se observa en los siguientes testimonios, "Los daños psicológicos no fueron tanto pero los económicos y materiales si fueron muchos". (Testimonio). "Para mí significa un abuso de la... de pronto de la misma vida porque... víctima en una sola vez bien pero ya una, dos veces y tres veces eso ya es 
mucho como, mucho". (Testimonio). Este inventario de pérdidas sin duda han afectado el capital social del país, en un posible escenario de posconflicto, requerirá unos mínimos para restablecer el derecho a los cerca de seis millones de víctimas, cexistirá presupuesto para ello?

La reparación simbólica como principio en la Ley 1448 de 2011, presenta retos importantes y si bien es cierto se ha avanzado en este aspecto, nunca podría sustituir la reparación material pues deben ir conjuntamente. El reconocimiento del sufrimiento, daños y pérdidas significa mucho para las familias, así lo expresan en los siguientes testimonios. "Pues sí, porque tuvimos que salir todos de alguna manera. Salimos todos de allá, de pronto sería la vida más diferente", (Testimonio); "para mí el daño es destrozarle a uno todo el corazón, la vida todo. Eso para mí es el daño. Yo estoy destrozada en este momento, no lo demuestro pero estoy destrozada moralmente", (Testimonio); de hecho yo no me considero víctima, ni me he metido en el plano de víctima, si no en el plano de que se me deben garantizar unos derechos "vida, honra y bien" nosotros de hecho nos hemos visto violentados en esto, hemos tenido que abandonar, nuestra cultura nuestras relaciones sociales nuestro entorno, nuestras labores. Porque de hecho aquí somos un estorbo". (Testimonio). Lo anterior demuestra la necesidad de fomentar la participación activa de las víctimas, del Estado, los actores armados y la sociedad civil para construir en conjunto, un escenario de posconflicto donde se garantice, la equidad e inclusión social, la justicia, la paz y por ende la reconciliación nacional.

\section{Reflexión}

e la teoría y testimonios arriba presentados podemos deducir la manera como las familias en situación de desplazamiento abordan los procesos de negociación y posible posconflicto en el país, ante los cual es claro que muchas de ellas no han logrado elaborar el duelo de las múltiples pérdidas que el conflicto armado les generó, sin embargo su principal apuesta es hacia la paz, pero con justicia, porque no podría ignorarse el profundo daño generado por los actores armados.

Es importante considerar las múltiples re-victimizaciones de los cuales son objeto las familias víctimas del desplazamiento forzado y la falta de respuesta estatal al respecto, por tanto la construcción de escenarios de reconciliación debe partir de generar procesos de inclusión social así como, reconstrucción del tejido social, solo de esta manera lograremos una paz duradera.

Se observa cierto escepticismo frente a la paz en parte de las familias ante la posibilidad de una culminación definitiva del conflicto armado, para ellos es claro que mientras prevalezcan las desigualdades sociales las situación de 
guerra no acabará. Estas familias plantean un no futuro de ambientes de paz, unos contextos donde se requiere aprender a convivir, a tolerar las nuevas situaciones, a aceptar las diferencias de regiones, donde cada actor debe poner de su parte, pero fundamentalmente con equidad social.

Sin duda será necesario un compromiso del Estado, de los actores armados, de la sociedad en general para lograr dignificar a las víctimas del conflicto armado en el país, pues desde sus relatos se observan que prevalecen sentimientos de discriminación y segregación social. Un compromiso que cada uno debe asumir tanto para aceptar su nueva condición como para entender, incluir y convivir en los nuevos escenarios, viendo el pasado como una experiencia de la que hay que sacar aprendizaje, capitalizarlo para crear entre todos ese nuevo escenario de paz, donde la justicia sea la consecuencia inmediata. El posconflicto es un escenario que podemos co-crear entre todos, es un sueño que debemos convertir en realidad pronto, donde cada grano de arena va a dar como producto una nueva sociedad con niños, niñas, adolescentes, jóvenes y adultos conviviendo en perfecta armonía.

\section{BIBLIOGRAFÍA}

AGUILAR, J. \& GARCÍA, J. (2014). "Análisis del programa de restitución de tierras frente al estado de cosas inconstitucional declarado por la Corte Constitucional mediante Sentencia T-025 de 2004".

ALCALDÍA DE SOACHA (2012) "Bienestar para todos y todas plan de desarrollo 2012-2015". http:// Www.soacha-cundinamarca.gov.co/apc-aa- files/65653566303431363662343131363535/ Plan_Desarrollo_2012_2015.pdf. Consultado 15 de marzo de 2015.

ARCE ORTIZ, J. P. \& MORENO SALAZAR, M. I. (2014). "Estándares internacionales en materia de reparación integral, su devenir y ejecución en el conflicto colombiano".

ARCHILA, M. \& PARDO, M. (2001). Movimientos sociales, Estado y democracia en Colombia. Universidad Nacional de Colombia, Centro de Estudios Sociales.

BEJARANO, J. (1999). Ensanchando el centro: El papel de la sociedad civil en el proceso de paz. Monsalve, A. Y Domínguez, E. (comp.) en Colombia: democracia y paz, Medellín, U. de A., UPB y CISC.

BAUTISTA REVELO, A. J. (2012). Restitución ¿̇realidad o ficción? Balance de los derechos de las víctimas del despojo y del abandono forzado de tierras en Colombia.

CASTEllanos, E. (2014). Discurso e ideología de Álvaro Uribe Vélez sobre las guerrillas colombianas y su impacto en los procesos de paz en Colombia. Discurso \& Sociedad, (2), 182-209. 
CODHES. (2013). "El desplazamiento forzado y la imperiosa necesidad de la paz". Informe .2013.http://static.iris.net.co/semana/upload/documents/Documento_391297_20140611.pdf. Consultado. 15 de marzo.

CORTÉS, P. M. (2013). Ley de víctimas y restitución de tierras en Colombia en contexto.

GARCÍA INDA, A. (2011). Derecho o barbarie. Apuntes sobre la relegitimación de la guerra. En G. Gallego García \& M. González Ordovías (Coord.), Conflicto armado interno, derechos humanos e impunidad. Bogotá, D. C.: Siglo del Hombre Editores - Universidad EAFIT - Universidad de Zaragoza - AECID.

GIRALDO, J. (2004). Búsqueda de verdad y justicia: seis experiencias en posconflicto. Cinep.

DE LA NACión, P. G., DEL PUEblo, D., \& COMPLETO, I. "Segundo informe de seguimiento a la Ley 1448 de 2011 de Víctimas y Restitución de Tierras".

DE MEMORIA HISTÓRICA, G. (2013). iBasta ya. Colombia: Memorias de guerra y dignidad.

DELGADO, E. H. (2009). Resistencias para la paz en Colombia. Experiencias indígenas, afrodescendientes y campesinas. Revista de Paz y Conflictos, 2, 117-135.

DUQUE MUÑOZ, L. \& GUEVARA ALZATE, A. F. (2014). "Las tensiones sociales producto de la desmovilización y reintegración de grupos guerrilleros y paramilitares".

HERNÁNDEZ DELGADO, E. \& SALAZAR POSADA, M. (1999). Con la esperanza intacta: Experiencias comunitarias de resistencia civil no violenta. Oxfam.

LUNA JARAMILLO, A. M. (2014). La restitución de tierras en Colombia: un instrumento para reparar las víctimas del conflicto armado o un instrumento político para el desarrollo económico.

LOAIZA, A. G. (2012). Negociaciones de paz en Colombia, 1982-2009. Un estado del arte. Estudios políticos, 40, 175-200

MEDINA, M. \& SÁNCHEZ, E. (Eds.). (2003). Tiempos de paz: acuerdos en Colombia, 1902-1994. Alcaldía Mayor de Bogotá. citado por; Nasi, C., \& Rettberg, A. (2005). Los estudios sobre conflicto armado y paz: un campo en evolución permanente. Colombia internacional, (62), 64-85.

MINISTERIO DE INTERIOR Y JUSTICIA. (2011). "Justicia transicional. Aportes para construir un lenguaje unificado de transición en Colombia". Bogotá. http://www.corteidh.or.cr/ tablas/29500.pdf . consultado 15 de marzo.

UNIDAD NACIONAL PARA LA ATENCIÓN Y REPARACIÓN INTEGRAL A LAS VÍCTIMAS. (2013). Desplazamiento y crisis humanitaria 2012-2013. http://Www.unidadvictimas.gov. co/index.php/91-intranet/2492-informe-desplazamiento-y-crisis-humanitaria-2012-2013. Consultado 15 marzo de 2015. 


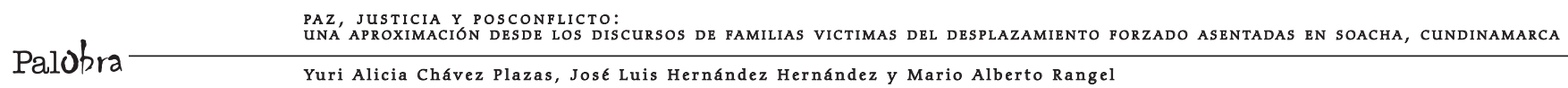

UPRIMNY, R. (2006) "Las enseñanzas del análisis comparado: procesos transicionales, formas de justicia transicional y el caso colombiano. ¿Justicia transicional sin transición? Verdad, justicia y reparación".

RETTBERG, A. (2003). Diseñar el futuro: Una revisión de los dilemas de la construcción de paz para el postconflicto. Revista de Estudios Sociales, (15), 15-28.

SACIPA RODRÍGUEZ, S. (2005). Las y los ciudadanos de Bogotá significan la paz 1. Universitas Psychologica, 4(1), 97-106.

VALENCIA, L. (2002). Adiós a la política, bienvenido la guerra: Secretos de un malogrado proceso de paz. Intermedio. citado por; Nasi, C., \& Rettberg, A. (2005). Los estudios sobre conflicto armado y paz: un campo en evolución permanente. Colombia internacional, (62), 64-85. 


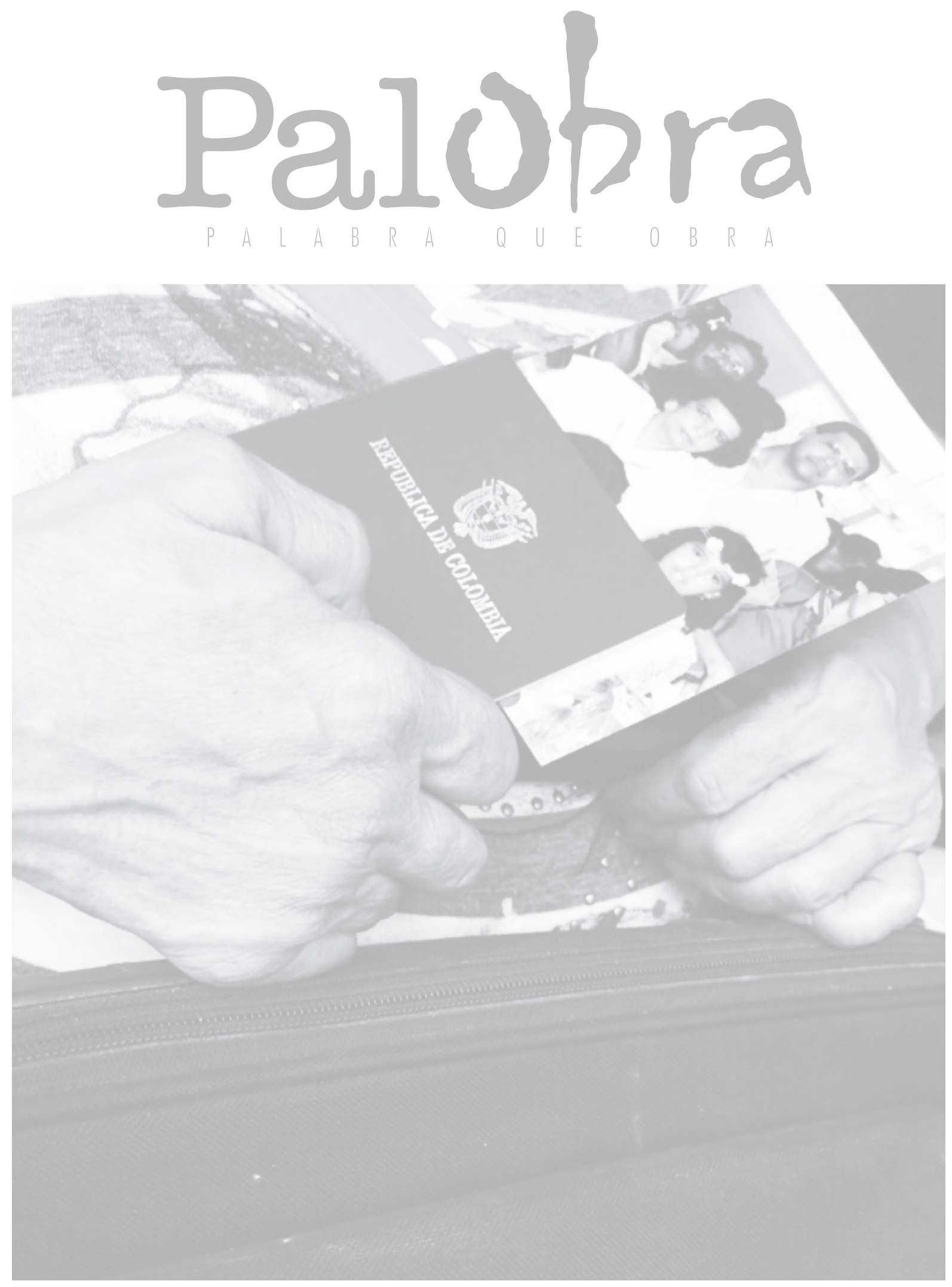

Foto: Lina Paz 